\title{
Serum IGF-I, its major binding protein (IGFBP-3) and epithelial ovarian cancer risk: the European Prospective Investigation into Cancer and Nutrition (EPIC)
}

\begin{abstract}
Petra H M Peeters, Annekatrin Lukanova ${ }^{1}$, Naomi Allen², Franco Berrino ${ }^{3}$, Tim Key ${ }^{2}$, Laure Dossus ${ }^{4}$, Sabina Rinaldi ${ }^{4}$, Carla H van Gils, H Bas Buenode-Mesquita ${ }^{5}$, Heiner Boeing ${ }^{6}$, Mandy Schulz ${ }^{6}$, Jenny Chang-Claude ${ }^{7}$, Jakob Linseisen ${ }^{7}$, Salvatore Panico ${ }^{8}$, Carlotta Sacerdote ${ }^{9}$, Domenico Palli ${ }^{10}$, Rosario Tumino ${ }^{14}$, Antonia Trichopoulou ${ }^{12}$, Dimitrios Trichopolos ${ }^{12}$, Christina Bamia ${ }^{12}$, Nerea Larranaga ${ }^{13}$, Eva Ardanaz ${ }^{14}$, Guillem Pera ${ }^{15}$, $J$ Ramón Quirós ${ }^{16}$, Carmen Martínez-García ${ }^{17}$, Carmen Navarro ${ }^{18}$, Sheila A Bingham ${ }^{19}$, Kay-Tee Khaw ${ }^{20}$, Françoise Clave ${ }^{21}$, Anne Tjonneland ${ }^{2}$, Anja Olsen ${ }^{22}$, Kim Overvad ${ }^{23}$,Mette S Tetsche ${ }^{23}$, Éliv Lund ${ }^{24}$, Eva Lundin ${ }^{25}$, Göran Berglund ${ }^{26}$, Elio Riboli' ${ }^{27}$ and $R$ Kaaks $^{4}$
\end{abstract}

\footnotetext{
Julius Center for Health Sciences and Primary Care, University Medical Center Utrecht, Utrecht, The Netherlands ${ }^{1}$ Department of Obstetrics and Gynecology, New York University School of Medicine, New York, New York, USA

${ }^{2}$ Epidemiology Unit, Cancer Research UK, University of Oxford, Richard Doll Building, Oxford, UK

${ }^{3}$ National Cancer Institute, Milan, Italy

${ }^{4}$ IARC International Agency for Research on Cancer (IARC-WHO), Lyon, France

${ }^{5}$ Center for Nutrition and Health, National Institute of Public Health and the Environment, Bilthoven, The Netherlands

${ }^{6}$ Department of Epidemiology, German Institute of Human Nutrition, Potsdam-Rehbrucke, Germany

${ }^{7}$ Clinical Epidemiology, German Cancer Research Center, Heidelberg, Germany

${ }^{8}$ Department of Clinical and Experimental Medicine, Federico II University, Naples, Italy

${ }^{9} \mathrm{CPO}-$ Piemonte, Torino, Italy

${ }^{10}$ Molecular and Nutritional Epidemiology Unit, CSPO-Scientific Institute of Tuscany, Florence, Italy

${ }^{11}$ Cancer Registry, Azienda Ospedaliera Civile M.P. Arezzo, Ragusa, Italy

${ }^{12}$ Department of Hygiene and Epidemiology, School of Medicine, University of Athens, Athens, Greece

${ }^{13}$ Public Health Division of Gipuzkoa, Health Department of the Basque Country, San Sebastian, Spain

${ }^{14}$ Public Health Institute of Navarra, Pamplona, Spain

${ }^{15}$ Epidemiology department (SERC), Catalan Institute of Oncology, Barcelona, Spain

${ }^{16}$ Public Health and Health Planning Directorate, Asturias, Spain

${ }^{17}$ Andalusian School of Public Health, Granada, Spain

${ }^{18}$ Department of Epidemiology, Murcia Health Council, Murcia, Spain

${ }^{19}$ MRC Dunn Human Nutrition Unit, Welcome Trust/MRC Building, Cambridge, UK

${ }^{20}$ Clinical Gerontology Unit, Addenbrooke's Hospital, Cambridge, UK

${ }^{21}$ Inserm E3N-EPIC, Institute Gustave Roussy, Villejuif, France

${ }^{22}$ Institute of Cancer Epidemiology, Danish Cancer Society, Copenhagen, Denmark

${ }^{23}$ Department of Clinical Epidemiology, Aalborg Hospital, Aarhus University Hospital, Aalborg, Denmark

${ }^{24}$ Institute of Community Medicine, University of Tromso, Tromso, Norway

${ }^{25}$ Biomedical Sciences/Pathology and Department of Public Health and Clinical Medicine, University of Umeå, Umeå, Sweden

${ }^{26}$ Department of Medicine, Lund University, Malmö, Sweden

${ }^{27}$ Department of Epidemiology \& Public Health, Faculty of Medicine, Imperial College London, St Mary's Campufs, Norfolk Place, London, UK

(Requests for offprints should be addressed to R Kaaks who is now at Division of Cancer Epidemiology, German Cancer Research Center (DKFZ), Im Neuenheimer Feld 280, 69120 Heidelburg, Germany; Email: r.kaaks@dkfz-heidelberg.de)
}

\begin{abstract}
We set out to study the relationship between circulating levels of IGF-I and its major binding protein (IGFBP-3) in relation to ovarian cancer risk. We conducted a case-control study nested within the European Prospective Investigation into Cancer and Nutrition. Levels of IGF-I and IGFBP-3 were measured in prediagnostic serum samples of 214 women who subsequently
\end{abstract}


developed ovarian cancer, and 388 matched control subjects. Conditional logistic regression models were used to estimate relative risks of ovarian cancer by tertiles of IGF-I and IGFBP-3 levels. For all women, there was no association between the circulating IGF-I or IGFBP-3 levels and the risk of ovarian cancer. However, among women diagnosed with ovarian cancer aged 55 or younger, the relative risk was higher in the middle or top tertiles of serum IGF-I, when compared with women in the lowest tertile (odds ratios $(\mathrm{OR})=1.8(95 \% \mathrm{Cl} 0.7-4.3)$ and $\mathrm{OR}=2.4(95 \% \mathrm{Cl}$ $0.9-6.4) ; P_{\text {trend }}=0.08$ ) respectively. These results were adjusted for body mass index, previous hormone use, fertility problems, and parity. Restricting the analysis to women who were premenopausal at blood donation, relative risks for ovarian cancer diagnosed before age 55 were higher $(\mathrm{OR}=5.1(95 \% \mathrm{Cl} 1.5-18.2)$ and $\mathrm{OR}=5.6(95 \% \mathrm{Cl} 1.5-20.8)$ respectively, for second and third tertiles; $P_{\text {trend }}=0.02$ ). Adjustment for serum IGFBP-3 levels only slightly attenuated relative risk estimates. Relations between IGFBP-3 and ovarian cancer before age 55 were in the same direction as for IGF-I, but less strong and statistically not significant. In women aged over 55 , there was no association between serum IGF-I or IGFBP-3 and ovarian cancer risk. Our results suggest that the circulating levels of IGF-I may play a potentially important role in the development of ovarian cancer in women of a pre- or perimenopausal age.

Endocrine-Related Cancer (2007) 14 81-90

\section{Introduction}

Ovarian cancer is the most fatal of all gynecologic tumors and the fourth most frequent cause of cancer death in women from North America and Northwestern European countries (Ferlay et al. 2001). Most epithelial ovarian tumors are diagnosed at advanced stage and the overall 5-year survival rate is below 50\%, largely unchanged during the last decades (Sant et al. 2003, Levi et al. 2004, Jemal et al. 2005). So far, there is a lack of clear understanding of the mechanisms underlying the effect of established risk factors for the disease (e.g., nulliparity, oral contraceptive use, and infertility) and the pathogenesis, early diagnosis, and treatment of ovarian cancer remain a major challenge.

Several specific hypotheses about ovarian carcinogenesis have been proposed, implicating incessant ovulation (Fathalla 1971), gonadotropins (Cramer \& Welch 1983), and steroid hormones (Cramer \& Welch 1983, Risch 1998) as key etiologic factors. More recently, the hormone/insulin-like growth factor-I (IGF-I) axis has also been hypothesized to play a possible role in the development of several tumor types (Pollak et al. 2004), including ovarian tumors (Kalli \& Conover 2003, Lukanova \& Kaaks 2005).

In a case-control study, protective effects were observed for higher levels of IGF-I (not statistically significant) and IGFBP-3 (statistically significant; Dal Maso et al. 2004). But, prospective studies have an advantage over retrospective case-control studies, where biomarker collection is done after the disease already has occurred. The implication is that in casecontrol studies, blood levels may have changed due to presence or treatment of the disease (Dal Maso et al. 2004). So far, only one prospective epidemiologic study has addressed the hypothesis that higher circulating levels of IGF-I increase ovarian cancer risk. In that study, which combined a total of 132 incident ovarian cancer cases from three different cohorts in New York, Umeå (Northern Sweden) and Milan (Italy), there was no overall relation between prediagnostic blood levels of IGF-I and ovarian cancer risk. However, for cancers diagnosed before age 55, IGF-I was strongly and directly associated with risk: women with IGF-I in the top tertile had approximately fivefold higher risk, in comparison with women in the bottom tertile (Lukanova et al. 2002a). The major binding peptide for IGF-I is IGFBP-3. We therefore set out to study the relation between prediagnostic IGF-I and IGFBP-3 levels and ovarian cancer in the largest ongoing European study on nutrition, metabolism, and cancer, the European Prospective Investigation into Cancer and Nutrition (EPIC; Riboli et al. 2002, Bingham \& Riboli 2004).

\section{Materials and methods}

\section{The EPIC cohort: baseline data collection}

EPIC recruitment procedures and collection of questionnaire data, anthropometric measurements, and blood samples have been described in detail previously (Riboli et al. 2002). In brief, extensive standardized questionnaire data on diet and non-dietary variables and anthropometric measurements were collected between 1992 and 1998, from over 366000 women and 153000 men living around 23 research centers spread over ten western European countries. About 246000 women and 140000 men also provided a blood sample. The present study includes ovarian 
cancer cases occurring after blood collection, and matched control subjects, from 19 out of the 23 recruitment centers, in eight out of the ten participating countries: Denmark, France, Germany, Greece, Italy, The Netherlands, Spain, and the United Kingdom. Norway was not included in the present study because blood samples have been collected only recently on a subsample of cohort participants, and only very few cases of ovarian cancer $(n<5)$ had accumulated after blood donation. Sweden was not included because of limited questionnaire information at the time of blood donation about menopausal status, past and current oral contraceptive use, and phase of menstrual cycle (Malmo) and because ovarian cancer patients had already been included in a previous study (Umea; Lukanova et al. 2002a).

Questionnaire data on non-dietary lifestyle and health factors included menstrual and reproductive history, present and previous use of oral contraceptives (OC) and postmenopausal hormone replacement therapy (HRT), history of previous illness and disorders or surgical operations, lifetime history of tobacco smoking and consumption of alcoholic beverages, physical activity, level of education and socioeconomic status, and brief occupational history. Completely standardized questionnaires were used in all eight countries contributing to the present study. In all countries included in the present analysis, except part of the cohort recruited through the Oxford research centre, height, weight, and waist and hip circumferences were measured to the nearest centimeter (height, body circumferences) and kilogram (weight) according to the standardized protocols, in light dressing. In part of the Oxford cohort, height, weight, and body circumferences were self-reported (Haftenberger et al. 2002).

\section{Collection and storage of blood samples}

Non-fasting blood samples (at least $30 \mathrm{ml}$ ) were drawn from participants in the eight countries contributing to the present study. All samples except for those from the Oxford center were stored at $5-10{ }^{\circ} \mathrm{C}$ and protected from light from the time of collection through their transfer to local laboratories, where they were further processed and separated into aliquots. For study subjects recruited through the Oxford center, blood samples were collected by a network of general practitioners in the United Kingdom and transported to a single laboratory in Norfolk by mail; they were protected from light but were exposed to ambient temperature. For participants in seven out of the eight countries included in the present study (i.e., all except Denmark), $0.5 \mathrm{ml}$ aliquots of the blood fractions (serum, plasma, red cells, and buffy coat for DNA extraction) were placed in 28 plastic straws (12 aliquots of plasma, 8 aliquots of serum, 4 aliquots of erythrocytes, and 4 aliquots of buffy coat), which were heat-sealed and stored in liquid nitrogen $\left(-196{ }^{\circ} \mathrm{C}\right)$; half of the aliquots (i.e., six aliquots of plasma, four aliquots of serum, two aliquots of erythrocytes and two aliquots of buffy coat) were stored in each of the local research centers, and the other half were stored centrally at the IARC. In Denmark, $1 \mathrm{ml}$ aliquots of the blood fractions were placed into Nunc tubes and stored in the vapor phase of liquid nitrogen containers $\left(-150^{\circ} \mathrm{C}\right)$.

\section{Determination of menopausal status and phase of menstrual cycle at blood donation}

Women were considered premenopausal at the time of blood donation when they reported they were still menstruating regularly over the past 12 months. Women were postmenopausal when the last menstrual period was more than 12 months before the recruitment date. When questionnaire data were missing or incomplete, women were considered premenopausal when they were younger than 42 years and postmenopausal when they were older than 55 years. Women between 42 and 55 years of age with missing or incomplete questionnaire data or with irregular cycles in the past 12 months were considered to be of undefined menopausal status.

Phase of menstrual cycle at blood donation was determined using 'forward' dating, i.e., counting from the women's reported dates of the start of their last menses. When the date of blood donation differed by more than 40 days from a woman's nearest reported date of last menstrual periods, menstrual cycle phase was left undetermined.

\section{Follow-up for cancer incidence and vital status, and selection of study subjects}

In Denmark, Italy, The Netherlands, Spain, and the United Kingdom, incident cancer cases were identified through record linkage with regional cancer registries. In France, Germany, and Greece follow-up was based on a combination of methods, including checking of health insurance records, cancer and pathology registries, and active follow-up through study subjects and their next-of-kin. Data on vital status in most EPIC study centers were collected from mortality registries at the regional or national level, in combination with data collected by active follow-up (Greece). For each EPIC study centre, closure dates of the study period were defined as the latest dates of complete follow-up 
for both cancer incidence and vital status (dates varied between centers between January 1999 and June 2003).

Study subjects (ovarian cancer patients and matched control subjects) were selected from among the women in each cohort who had not been previously diagnosed with cancer (except for non-melanoma skin cancer). Case subjects were women who developed ovarian cancer after the date of blood donation and before the end of the study period, defined for each study centre by the latest end-date of follow-up. Cases were coded according to the 10th Revision of the International Statistical Classification of Diseases, Injuries, and Causes of Death.

For each case subject, two control subjects were chosen at random among appropriate risk sets consisting of all cohort members alive and free of cancer (except non-melanoma skin cancer) at the time of diagnosis of the index case. An incidence density sampling protocol for control selection was used. Matching criteria included study centre, menopausal status (pre, post, 'undefined'), age at enrolment ( \pm 6 months), time of the day of blood collection $( \pm 1 \mathrm{~h})$ and, for premenopausal women, phase of menstrual cycle ('early follicular' (days 0-7 of the cycle), 'late follicular' (days 8-11), 'periovulatory' (days 12-16), 'mid-luteal' (days 20-24), and 'other luteal' (days $17-19$ or $25-40)$ ). The cases and controls were also matched on time between blood draw and last consumption of foods or drinks $(<3,3-6,>6 \mathrm{~h})$, in view of further studies in which ovarian cancer risk will be related to endogenous insulin levels.

A total of 529 women with ovarian cancer were reported to the international EPIC database. Prediagnostic blood samples were available for 356 women. Excluded were metastatic ovarian cancer and nonepithelial tumors $(n=32)$, cases who were using exogenous hormones at the time of blood donation $(n=88)$, cases who reported (uni or bilateral) ovariectomy or hysterectomy $(n=12)$, cases for whom serum straws were missing $(n=3)$, and cases without control samples $(n=7)$. During blood donation, women who reported that they used exogenous hormones for contraception or medical purposes were excluded because in this case-control study we plan to measure also the levels of sex steroids. In addition, in some women, hormone use may affect the levels of the peptides of the IGF-I signaling pathway (Suikkari et al. 1991). Exclusion of hysterectomized women was done because we were not sure whether a self-reported hysterectomy operation did not include removal of one or two ovaries. Although we do not have data or references for this hypothesis, we believe that elderly women (in the 1990s) perhaps in some countries may not have been correctly informed about their operation, or may not have completely understood the operation. We therefore decided to exclude all women who reported a hysterectomy (or removal of the ovary (ovaries)) from the case and control group. A total of 214 ovarian cancer cases were available for analysis. The histological distribution of the cases was: serous $102(47.5 \%)$, mucinous 14 (6.5\%), endometroid cases 25 (11\%), clear cell 9 (4\%), and $64(30 \%)$ were classified as other (missing, 15; unspecified, 46; or undifferentiated, 3). These included 44 cases in Denmark, 44 in Italy, 37 in Spain, 31 in the UK, 30 in The Netherlands, 13 in Greece, 8 in France, and 7 in Germany.

For the present analysis, a total of 388 control subjects were matched to the 214 ovarian cancer cases.

All participants had given their written informed consent for future analyses of their blood samples, and the Internal Review Boards of IARC and each of the recruitment centers had approved this study.

\section{Hormone assays}

Serum assays of IGF-I and IGFBP-3 were performed at the International Agency for Research on Cancer (Nutrition and Hormones Group), Lyon, France. Samples from ovarian cancer cases and their matched control subjects were always analyzed in the same assay kit. Laboratory personnel were unable to distinguish among case and control samples. Three different serum samples were inserted in each batch for quality control. Peptide concentrations were measured by ELISAs with reagents from Diagnostic Systems Laboratories (DSL, Webster, Texas, USA). Total IGF-I was measured after an acid-ethanol precipitation of IGF-I binding proteins, to avoid interference of IGFBPs with the IGF-I assay.

The mean intra-batch coefficients of variation were $2.5 \%$ for an IGF-I concentration of $6.5 \mathrm{nmol} / \mathrm{l}$ and $3.7 \%$ for an IGFBP-3 concentration of $140 \mathrm{nmol} / \mathrm{l}$. The mean inter-batch coefficients of variation were $12.2 \%$ for an IGF-I concentration of $13 \mathrm{nmol} / \mathrm{l}$, and $6.9 \%$ for an IGFBP-3 concentration of $140 \mathrm{nmol} / \mathrm{l}$.

\section{Statistical analyses}

In all analyses, levels of IGF-I and IGFBP-3 were logtransformed to normalize their distributions. Relative risks (odds ratios, OR) were calculated by conditional logistic regression models. Hormone levels were categorized into tertiles. Cut-points were based on the distributions in the control subjects, from all EPIC centers combined. This implies that cut-points are different in subgroup analyses. Likelihood ratio tests 
were used to assess linear trends in odds ratios with assigned mean levels for the tertile categories. Confidence intervals (95\%) were computed using the standard errors of the pertinent regression coefficients. Potential confounders included body mass index (BMI), age at menarche, parity, number of children, age at first full-term birth, fertility problems (selfreported), breast feeding, and smoking. They were first individually checked and only those covariates that changed the logistic $\beta$-coefficient of the 'IGF-tertile' variable by more than $10 \%$ were taken together into the multivariate logistic model. The fully adjusted model included BMI (BMI in quartiles: <23.6; 23.6-26.1; 26.1-29.2; $\geq 29.3$ ), previous HRT (HRT use: yes, no, missing), previous use of OC (OC use: yes, no, missing), ever had fertility problems (yes, no, unknown), and parity (yes, no, unknown). Both models were also adjusted for IGFBP-3 (when analyzing IGF-I) and IGF-I levels (when analyzing IGFBP-3).

Statistical analyses were performed in the full study population, as well as in the subgroups of women younger or equal to age 55 at ovarian cancer diagnosis (66 cases) and a diagnosis after the age of 55 (148 cases). A more extreme subgroup was defined as women with a cancer diagnosis before age 55 and premenopausal at study recruitment (49 cases).

Analyses were repeated after excluding all ovarian cancers that were diagnosed within 2 years after blood donation. Country-specific numbers were too small to test for heterogeneity of odds ratio estimates between countries.

\section{Results}

This study includes 214 cases diagnosed after recruitment (time of blood donation): 56 were premenopausal at recruitment, 136 were postmenopausal, and 22 were of undefined status. Among the cases, the mean time between recruitment and diagnosis was 3.3 years (range, 0.06-7.9 years) for women who were premenopausal at blood donation, and 3.4 years (range, 0.11-9.3 years) for women who were postmenopausal. The median age at cancer diagnosis was 60 years (range, 37-78 years), 49 years (range, 37-61 years) for women who were premenopausal at the time of blood donation, and 64 years (range, 52-78 years) for women who were postmenopausal.

Overall, the ovarian cancer cases were heavier than control subjects (BMI 26.4 vs 25.8; $P=0.04$; Table 1 ). A higher proportion of cases were nulliparous when compared with controls (20.1 vs $12.6 \% ; P=0.007)$, parous cases also had fewer children when compared with parous control subjects $(P=0.02)$. Previous oral contraceptive use was somewhat lower in cases $(38.8$ vs $42.8 \%$, ns), while previous use of HRT was similar in cases and control subjects. Ages at both menarche and menopause were similar.

Geometric mean levels for IGF-I were $23.4 \mathrm{nmol} / \mathrm{l}$ (95\% CI 22.2-24.8) and $23.8 \mathrm{nmol} / \mathrm{l}$ (95\%CI 22.8-24.8) for cases and controls respectively and geometric mean levels for IGFBP-3 were $155 \mathrm{nmol} / \mathrm{l}$ (95\%CI 151-160) both for cases and controls. Serum levels of IGF-I showed statistically significant inverse correlations with age at blood donation, in both premenopausal $(r=-0.25)$ and postmenopausal women $(r=-0.23)$, and weaker negative correlations were observed between age and IGFBP-3. Adjusting for age, as well as for analytical batch and case-control status, Pearson partial correlation coefficients between IGF-I and IGFBG-3 were above $0.57(P<0.0001)$ in both pre- and postmenopausal women. By contrast, there was no significant correlation of either IGF-I or IGFBP-3 with BMI.

Overall, in all age groups combined, serum levels of IGF-I or IGFBP-3 showed no relationship with ovarian cancer risk (Table 2). Adjusting for BMI, previous use of OC or HRT, fertility problems, parity, or serum IGFBP-3 levels did not change these results. However, for women who were diagnosed with ovarian cancer at the age of 55 or before, relative risks were higher, although not significantly so, for women in the middle or top tertiles of IGF-I, when compared with women in the lowest tertile $(\mathrm{OR}=1.8(95 \% \mathrm{CI}$ 0.7-4.3) and $\left.\mathrm{OR}=2.4 \quad(95 \% \mathrm{CI} \quad 0.9-6.4) ; P_{\text {trend }}=0.08\right)$. Further adjustment for IGFBP-3 only slightly attenuated these relative risk estimates. When defining a more extreme cut-off point for age at diagnosis, i.e., 50 years ( $n=37$ cases), the relative risk estimates for the middle and top tertiles were higher $(\mathrm{OR}=2.7$ (95\% CI 0.9-8.4) and $\mathrm{OR}=3.2(95 \% \mathrm{CI} 1.0-10.2))$, with a close-to significant trend $\left(P_{\text {trend }}=0.06\right)$. When we restricted our analyses to women who were premenopausal at blood drawn and who were under the age of 55 years when ovarian cancer was diagnosed ( $n=49$ cases), statistically significant relative risk estimates were also observed $(\mathrm{OR}=5.1(95 \% \mathrm{CI} 1.5-18.2)$ and $\mathrm{OR}=5.6$ (95\% CI 1.5-20.8) respectively, for second and third tertiles; $P_{\text {trend }}=0.02$ ). In these latter, more restricted subgroup analyses, however, relative risk estimates showed rather wide confidence intervals due to very low numbers of cases in the reference category $(n=6$ for $<50$ at diagnosis and 7 for premenopausal and $<55$ ). Ovarian cancer risk relations with IGFBP-3 serum concentrations were on average in the same direction as for IGF-I levels, but these relations were less clear and statistically non-significant (Table 3). 
Table 1 Characteristics for ovarian cancer cases and control subjects

\begin{tabular}{|c|c|c|c|}
\hline & Cases $(n=214)$ & Controls $(n=388)$ & $P_{\text {diff }}$ \\
\hline \multicolumn{4}{|l|}{ Matching variables } \\
\hline \multicolumn{4}{|l|}{ Study centre } \\
\hline France & $3.7 \%$ & $3.1 \%$ & \\
\hline Italy & $20.6 \%$ & $21.7 \%$ & \\
\hline Spain & $17.3 \%$ & $18.3 \%$ & \\
\hline UK & $14.5 \%$ & $14.2 \%$ & \\
\hline The Netherlands & $14.0 \%$ & $12.6 \%$ & \\
\hline Greece & $6.1 \%$ & $6.7 \%$ & \\
\hline Germany & $3.3 \%$ & $3.4 \%$ & \\
\hline Denmark & $20.6 \%$ & $20.1 \%$ & 1.00 \\
\hline Age at blood donation & $56.7(40.4-68.5)$ & $56.1(39.7-68.4)$ & 0.36 \\
\hline \multicolumn{4}{|l|}{ Menopausal status } \\
\hline Premenopausal & $26.2 \%$ & $28.1 \%$ & \\
\hline Postmenopausal & $63.5 \%$ & $61.1 \%$ & \\
\hline Undefined menopausal & $10.3 \%$ & $10.8 \%$ & 0.84 \\
\hline \multicolumn{4}{|c|}{ Time of the day of blood collection } \\
\hline$<0800 \mathrm{~h}$ & $0.9 \%$ & $1.0 \%$ & \\
\hline $0800-1000 \mathrm{~h}$ & $35.4 \%$ & $36.9 \%$ & \\
\hline $1000-1200 \mathrm{~h}$ & $27.8 \%$ & $28.1 \%$ & \\
\hline $1200-1400 \mathrm{~h}$ & $16.0 \%$ & $14.8 \%$ & \\
\hline $1400-1600 \mathrm{~h}$ & $10.4 \%$ & $9.6 \%$ & \\
\hline $1600-1800 \mathrm{~h}$ & $5.7 \%$ & $4.9 \%$ & \\
\hline $1800-2000 \mathrm{~h}$ & $2.8 \%$ & $3.6 \%$ & \\
\hline$>2000 \mathrm{~h}$ & $0.9 \%$ & $1.0 \%$ & 1.00 \\
\hline \multicolumn{4}{|l|}{ Menstrual cycle phase } \\
\hline Early follicular & $26.7 \%$ & $27.0 \%$ & \\
\hline Late follicular & $17.8 \%$ & $15.7 \%$ & \\
\hline Periovulatory & $15.6 \%$ & $16.9 \%$ & \\
\hline Mid-luteal & $15.6 \%$ & $16.9 \%$ & \\
\hline Other luteal & $24.4 \%$ & $23.6 \%$ & 1.00 \\
\hline \multicolumn{4}{|l|}{ Fasting status } \\
\hline$<3 \mathrm{~h}$ & $44.9 \%$ & $44.0 \%$ & \\
\hline $3-6 \mathrm{~h}$ & $17.4 \%$ & $16.8 \%$ & \\
\hline$>6 \mathrm{~h}$ & $37.7 \%$ & $39.2 \%$ & 0.94 \\
\hline \multicolumn{4}{|l|}{ Other variables } \\
\hline Age at diagnosis & $60.0(44.0-72.0)$ & - & - \\
\hline Height & $160.0(150.0-171.0)$ & $160.6(149.0-171.8)$ & 0.21 \\
\hline Weight & $68.0(52.3-93.1)$ & $66.0(52.0-91.5)$ & 0.14 \\
\hline BMI & $26.4(21.0-35.8)$ & $25.8(19.9-36.3)$ & 0.04 \\
\hline Waist & $84.0(68.3-104.0)$ & $82.0(68.0-108.0)$ & 0.47 \\
\hline Waist-to-hip ratio & $0.81(0.70-0.92)$ & $0.80(0.71-0.95)$ & 0.26 \\
\hline Age at menarche & $13.0(11.0-16.0)$ & $13.0(11.0-16.0)$ & 0.31 \\
\hline Parous & $79.9 \%$ & $87.4 \%$ & 0.007 \\
\hline Age at first FTP & $25.0(19.0-32.0)$ & $24.0(19.0-32.0)$ & 0.14 \\
\hline Number of FTP ${ }^{a}$ & $2.0(1.0-5.0)$ & $2.0(1.0-4.0)$ & 0.02 \\
\hline Ever fertility problems & $1.9 \%$ & $2.8 \%$ & 0.52 \\
\hline Ever breast feeding & $68.7 \%$ & $70.6 \%$ & 0.27 \\
\hline Age at menopause & $50.0(43.0-56.0)$ & $50.0(40.0-56.0)$ & 0.17 \\
\hline Previous OC use & $38.8 \%$ & $42.8 \%$ & 0.26 \\
\hline Previous HRT use & $16.8 \%$ & $16.8 \%$ & 0.99 \\
\hline \multicolumn{4}{|l|}{ Smoking status } \\
\hline Never & $57.9 \%$ & $60.1 \%$ & \\
\hline Former & $21.5 \%$ & $18.8 \%$ & \\
\hline Current & $20.6 \%$ & $20.4 \%$ & 0.74 \\
\hline
\end{tabular}

Median (5th-95th percentiles) or percentages; missing values $<6 \%$ for all variables, except for 'ever fertility problems' (32\%).

${ }^{a}$ First full-term pregnancy (FTP) relies on parous women only. 
Table 2 Risk of ovarian cancer in relation to IGF-I ( $\mathrm{nmol} / \mathrm{I})$ tertiles for all women; for (A) women with ovarian cancer diagnosis at or before the age of 55 years and for women over the age of 55; for (B) women with a diagnosis before the age of 55 and premenopausal at recruitment

\begin{tabular}{|c|c|c|c|c|}
\hline & First tertile & Second tertile & Third tertile & $P_{\text {trend }}$ \\
\hline Tertile cut-points & $<20.4^{\mathrm{a}}$ & $20.5-28.1^{a}$ & $\geq 28.2^{\mathrm{a}}$ & \\
\hline ALL (cases/controls) & $76 / 128$ & $60 / 130$ & $78 / 130$ & \\
\hline Crude $^{b}$ & 1.0 & $0.8(0.5-1.2)$ & $1.0(0.7-1.6)$ & 0.93 \\
\hline Adjusted $^{c}$ & 1.0 & $0.8(0.5-1.2)$ & $1.1(0.7-1.7)$ & 0.84 \\
\hline A & $<25.3^{\mathrm{a}}$ & $25.3-33.0^{\mathrm{a}}$ & $\geq 33.1^{\mathrm{a}}$ & \\
\hline$\leq 55$ years (cases/controls) & $15 / 43$ & $24 / 41$ & $27 / 44$ & \\
\hline Crude (matched) $)^{\mathrm{b}}$ & 1.0 & $1.7(0.8-3.8)$ & $1.9(0.8-4.4)$ & 0.14 \\
\hline \multirow[t]{2}{*}{ Adjusted $^{\mathrm{c}}$} & 1.0 & $1.8(0.7-4.3)$ & $2.4(0.9-6.4)$ & 0.08 \\
\hline & $<16.8^{\mathrm{a}}$ & $16.8-24.9^{\mathrm{a}}$ & $\geq 25.0^{a}$ & \\
\hline$>55$ years (cases/controls) & $51 / 86$ & $48 / 85$ & $49 / 89$ & \\
\hline Crude (matched) ${ }^{\mathrm{b}}$ & 1.0 & $0.9(0.5-1.5)$ & $0.9(0.5-1.5)$ & 0.59 \\
\hline Adjusted $^{c}$ & 1.0 & $1.0(0.6-1.6)$ & $0.9(0.5-1.6)$ & 0.74 \\
\hline$B$ & $<25.4^{\mathrm{a}}$ & $25.4-34.5^{\mathrm{a}}$ & $\geq 34.6^{\mathrm{a}}$ & \\
\hline $\begin{array}{l}\leq 55 \text { years and premenopau- } \\
\text { sal/undefined (cases/con- } \\
\text { trols) }\end{array}$ & 7/33 & $22 / 32$ & $20 / 32$ & \\
\hline Crude (matched) ${ }^{\mathrm{b}}$ & 1.0 & $3.4(1.3-9.2)$ & $3.4(1.2-9.7)$ & 0.03 \\
\hline Adjusted $^{\mathrm{c}}$ & 1.0 & $5.1(1.5-18.2)$ & $5.6(1.5-20.8)$ & 0.02 \\
\hline
\end{tabular}

${ }^{\mathrm{a}}$ Tertiles were based on the distribution in controls, so limits are different for different control groups.

${ }^{b}$ Model 1 'Conditional regression models were conditioned on study centre, menopausal status, age, time of the day of blood collection, phase of menstrual cycle (for premenopausal women), time between blood drawn and last consumption of food/drinks'. 'See Model 1 and adjusted for BMI (in quartiles), previous HRT use (yes, no, missing), previous OC use (yes, no, missing), fertility problems (yes, no, missing), parity (parous, nulliparous, missing).

Table 3 Risk of ovarian cancer in relation to IGFBP-3 (nmol/l) tertiles for all women; and for $(\mathrm{A})$ women with ovarian cancer diagnosis at or before the age of 55 years and for women over the age of 55; for (B) women with a diagnosis before the age of 55 and premenopausal at recruitment

\begin{tabular}{|c|c|c|c|c|}
\hline & First tertile & Second tertfile & Third tertile & $P_{\text {trend }}$ \\
\hline Tertile cut-points & $<145.5^{\mathrm{a}}$ & $145.5-167.2^{\mathrm{a}}$ & $\geq 167.3^{a}$ & \\
\hline ALL (cases/controls) & $70 / 127$ & $60 / 129$ & $84 / 131$ & \\
\hline Crude (matched) ${ }^{\mathrm{b}}$ & 1.0 & $0.8(0.5-1.3)$ & $1.1(0.7-1.8)$ & 0.63 \\
\hline Adjusted $^{c}$ & 1.0 & $0.8(0.5-1.3)$ & $1.1(0.7-1.8)$ & 0.65 \\
\hline A & $<149.9^{a}$ & $149.9-170.6^{a}$ & $\geq 170.7^{\mathrm{a}}$ & \\
\hline$\leq 55$ years (cases/controls) & $17 / 42$ & $23 / 43$ & $26 / 42$ & \\
\hline Crude (matched) ${ }^{\mathrm{b}}$ & 1.0 & $1.4(0.6-3.0)$ & $1.6(0.7-3.6)$ & 0.28 \\
\hline \multirow[t]{2}{*}{ Adjusted $^{c}$} & 1.0 & $1.8(0.7-4.5)$ & $2.1(0.8-5.4)$ & 0.12 \\
\hline & $<142.6^{\mathrm{a}}$ & $142.6-163.9^{a}$ & $\geq 164.0^{\mathrm{a}}$ & \\
\hline$>55$ years (cases/controls) & $53 / 85$ & $36 / 87$ & $59 / 88$ & \\
\hline Crude (matched) ${ }^{\mathrm{b}}$ & 1.0 & $0.6(0.4-1.1)$ & $1.0(0.6-1.7)$ & 0.91 \\
\hline Adjusted $^{c}$ & 1.0 & $0.7(0.4-1.2)$ & $1.0(0.6-1.7)$ & 0.91 \\
\hline$B$ & $<149.7^{\mathrm{a}}$ & $149.7-168.6^{a}$ & $\geq 168.7^{a}$ & \\
\hline $\begin{array}{l}\leq 55 \text { years AND premenopau- } \\
\text { sal/undefined (cases/con- } \\
\text { trols) }\end{array}$ & 11/33 & $16 / 32$ & 22/32 & \\
\hline Crude $(\text { matched })^{\mathrm{b}}$ & 1.0 & $1.6(0.6-4.0)$ & $2.4(0.9-6.2)$ & 0.08 \\
\hline Adjusted $^{c}$ & 1.0 & $2.5(0.8-7.8)$ & $3.1(1.0-9.9)$ & 0.06 \\
\hline
\end{tabular}

${ }^{\text {a }}$ Tertiles were based on the distribution in controls, so limits are different for different control groups control groups.

${ }^{b}$ Model 1 'Conditional regression models were conditioned on study centre, menopausal status, age, time of the day of blood collection, phase of menstrual cycle (for premenopausal women), time between blood drawn and last consumption of food/drinks'. ${ }^{\mathrm{c}}$ See Model 1 and adjusted for BMI (in quartiles), previous HRT use (yes, no, missing), previous OC use (yes, no, missing), fertility problems (yes, no, missing), parity (parous, nulliparous, missing). 
Relative risk estimates were very similar when based on country-specific cut-points instead of the cutpoints determined on the control subjects of all countries combined. Although it is unclear during which period ovarian cancers were already present, we executed an analysis where we excluded all ovarian cancer cases that were detected $<2$ years after blood drawing $(n=69)$. Overall, results were the same, but not statistically significant.

\section{Discussion}

In this prospective study, we observed a direct relationship of serum IGF-I concentrations with ovarian cancer risk diagnosed before age 55 , with a 2- to 2.5-fold increase in risk for women in the highest, when compared with the lowest third of serum IGF-I. Although only of borderline significance, these results are consistent with those of the only other prospective study published to date (Lukanova et al. 2002a), which reported higher risks of ovarian cancer diagnosed before age 55 among women in the middle and top tertiles of IGF-I, when compared with the lower tertile $(\mathrm{OR}=1.7 \quad(95 \% \mathrm{CI} \quad 0.5-6.5)$ and $\mathrm{OR}=5.0(95 \% \mathrm{CI}$ $1.2-20.6)$ respectively; $\left.P_{\text {trend }}=0.03\right)$. No association was observed between IGF-I and risk of ovarian cancer diagnosed after age 55, and neither was there any association between serum IGFBP-3 concentrations and ovarian cancer risk, irrespective of age group.

IGF-I has well-documented mitogenic and antiapototic activity (Khandwala et al. 2000, Larsson et al. 2005) believed to mediate its effect on neoplastic development. Elevated prediagnostic circulating IGF-I has been associated with increased risks of several cancer types, including cancers of the breast, prostate, and colon (Chan et al. 1998, Hankinson et al. 1998, Ma et al. 1999, Stattin et al. 2000, Toniolo et al. 2000, Palmqvist et al. 2002). In the ovary, the IGF-I signaling system has a key role in the regulation of the normal function of the organ, including follicular growth, development, steroidogenesis, and atresia (Wang \& Chard 1999, Giudice 2001). IGF peptides, receptors, binding proteins (BPs), and BP proteases are all expressed in both normal and malignant ovarian epithelial cells (Lukanova \& Kaaks 2005). Studies in vitro have shown that the overexpression of IGF-I receptor can induce malignant transformation of ovarian epithelial cells (Coppola et al. 1999). Furthermore, initial evidence suggests that IGF-I receptor could be a potential new molecular target in ovarian cancer treatment (Gotlieb et al. 2006). Besides direct effects as a growth factor, it has also been hypothesized that IGF-I could promote ovarian tumor formation by modulating ovarian steroidogenesis (Risch 1998, Lukanova \& Kaaks 2005).

The reason for an adverse effect of elevated circulating IGF-I on ovarian tumorigenesis during reproductive age, but not later in life is unknown. Several hypotheses have been put forward to explain the effect modification by age (Hankinson et al. 1998): with increasing age, circulating levels of IGF-I reflect less accurately the influence of the GH/IGF-I axis during adolescence and early adulthood (Juul 2003). If this is important in ovarian carcinogenesis, relative risk will differ between old and young women. Association of ovarian cancer risk with tall stature will provide an indirect support for such theory as attained height strongly correlates with IGF-I during puberty, but not with hormone concentrations during adult life (Gunnell et al. 2004). However, the association of height with ovarian cancer is not consistent (Lukanova et al. 2002b, Engeland et al. 2003). Another explanation for age modification would be that the effect of IGF-I on cancer risk may be dependent of high background estrogen concentrations as observed before menopause. Furthermore, after menopause there is a progressive decrease not only in total IGF-I, but also in bioavailable IGF-I concentrations due to the less steep decrease of IGFBP-3 with age and the increased secretion of IGFBP-1 (Lukanova et al. 2001). Thus, with increasing age and with the approach of menopause, IGF-I signaling is substantially diminished and at a certain point of a women's life circulating IGF-I may be a poor indicator of its etiological relevance to cancer risk.

An additional consideration, with particular relevance to ovarian cancer is that tumor-promoting effects of hormones and growth factors, including IGF-I, may be especially relevant during remodeling of the ovarian surface epithelium after ovulation (Lund 1999), which would limit these effects mostly to women of premenopausal age. Further studies on the association of IGF-I with cancer risk, including samples obtained from women across a wide age-range, starting from early adulthood will be essential for our understanding of the role of this peptide in ovarian cancer.

The nested case-control design of our study has the advantage that cancer cases and control subjects could be selected from the same, well-defined source population, with careful matching for a number of potential confounders. This minimizes the risks of selection and confounding biases that may affect results from retrospective case-control studies. Another strength of our study was the availability of highly standardized and detailed data on potential confounding factors, such as previous use of OC or HRT, reproductive history or infertility problems. We carefully excluded women who 
had a previous diagnosis of cancer (except nonmelanoma skin tumors), who used exogenous hormones at the time of blood sampling, who had one or two ovaries removed, and who reported to have had hysterectomy. Finally, although our study has a multi-centre design, with study subjects from 19 recruitment centers in eight European countries, there was a very high degree of standardization across study centers of blood collection protocols and questionnaire data, and measurements of IGF-I and IGFBP-3 were made in one laboratory, with samples from cases and their matched controls always assayed in the same analytical batch.

Although the number of ovarian cancer cases was larger in this study than in the previous study by Lukanova et al. (2002a), numbers of cancer cases remained fairly low in subgroup analyses defined by age and menopausal status or by duration of follow-up, and did not allow us to examine different histological subtypes of ovarian cancer as separate endpoints. For serous ovarian cancers $(n=102)$, results were in the same direction but no longer statistically significant. Another limitation of our study was the lack of data about menopausal status at the time of ovarian cancer diagnosis. Since 'age' and 'menopausal status' are closely linked, it is not clear whether the observed effect in younger women is caused by age or by menopause.

In conclusion, this prospective cohort study provides some evidence that among (premenopausal) women risk of ovarian cancer before age 55 is possibly related to circulating levels of IGF-I, in agreement with observations from one previous prospective study.

\section{Acknowledgements}

The EPIC study was funded by 'Europe Against Cancer' Programme of the European Commission (SANCO); Ligue contre le Cancer (France); Société 3M (France); Mutuelle Générale de l'Education Nationale; Institut National de la Santé et de la Recherche Médicale (INSERM); German Cancer Aid; German Cancer Research Center; German Federal Ministry of Education and Research; Danish Cancer Society; Health Research Fund (FIS) of the Spanish Ministry of Health; the participating regional governments and institutions of Spain; Cancer Research UK; Medical Research Council, UK; the Stroke Association, UK; British Heart Foundation; Department of Health, UK; Food Standards Agency, UK; the Wellcome Trust, UK; Greek Ministry of Health; Greek Ministry of Education; Italian Association for Research on Cancer; Italian National Research Council; Dutch Ministry of Public Health, Welfare and Sports; Dutch Ministry of Health; Dutch Prevention Funds; LK Research Funds; Dutch ZON
(Zorg Onderzoek Nederland); World Cancer Research Fund (WCRF); Swedish Cancer Society; Swedish Scientific Council; Regional Government of Skane, Sweden; Norwegian Cancer Society; Specific study results of this case-control study nested within EPIC, presented in this paper, were obtained with financial support from the National Cancer Institute (USA) (grant no. 1U01CA98216-01). The authors declare that there is no conflict of interest that would prejudice the impartiality of this scientific work.

\section{References}

Bingham S \& Riboli E 2004 Diet and cancer - the European prospective investigation into cancer and nutrition. Nature Reviews. Cancer 4 206-215.

Chan JM, Stampfer MJ, Giovannucci E, Gann PH, Ma J, Wilkinson P, Hennekens CH \& Pollak M 1998 Plasma insulin-like growth factor-I and prostate cancer risk: a prospective study. Science 279 563-566.

Coppola D, Saunders B, Fu L, Mao W \& Nicosia SV 1999 The insulin-like growth factor I receptor induces transformation and tumorigenicity of ovarian mesothelial cells and down-regulates their Fas-receptor expression. Cancer Research 59 3264-3270.

Cramer DW \& Welch WR 1983 Determinants of ovarian cancer risk.II. Inferences regarding pathogenesis. Journal of the National Cancer Institute 71 717-721.

Dal Maso L, Augustin LS, Franceschi S, Talamini R, Polesel J, Kendall CW, Jenkins DJ, Vidgen E \& La Vecchia C 2004 Association between components of the insulin-like growth factor system and epithelial ovarian cancer risk. Oncology 67 225-230.

Engeland A, Tretli S \& Bjorge T 2003 Height, body mass index, and ovarian cancer: a follow-up of 1.1 million Norwegian women. Journal of the National Cancer Institute 95 1244-1248.

Fathalla MF 1971 Incessant ovulation - a factor in ovarian neoplasia? Lancet 2163.

Ferlay J, Bray F, Pisani P \& Parkin DM 2001 GLOBOCAN 2000: Cancer incidence, mortality, and prevalence worldwide. Version 1.0. Lyon, France: IARC Press.

Giudice LC 2001 Insulin-like growth factor family in Graafian follicle development and function. Journal of the Society for Gynecologic Investigation 8 S26-S29.

Gotlieb WH, Bruchim I, Gu J, Shi Y, Camirand A, Blouin MJ, Zhao Y \& Pollak MN 2006 Insulin-like growth factor receptor I targeting in epithelial ovarian cancer. Gynecologic Oncology 100 389-396.

Gunnell D, Oliver SE, Donovan JL, Peters TJ, Gillatt D, Persad R, Hamdy FC, Neal DE \& Holly JM 2004 Do height-related variations in insulin-like growth factors underlie the associations of stature with adult chronic disease? Journal of Clinical Endocrinology and Metabolism 89 213-218. 
Haftenberger M, Lahmann PH, Panico S, Gonzalez CA, Seidell JC, Boeing H, Giurdanella MC, Krogh V, Buenode-Mesquita HB, Peeters PH et al. 2002 Overweight, obesity and fat distribution in 50- to 64-year-old participants in the European Prospective Investigation into Cancer and Nutrition (EPIC). Public Health Nutrition 5 1147-1162.

Hankinson SE, Willett WC, Colditz GA, Hunter DJ, Michaud DS, Deroo B, Rosner B, Speizer FE \& Pollak M 1998 Circulating concentrations of insulin-like growth factor-I and risk of breast cancer. Lancet 351 1393-1396.

Jemal A, Murray T, Ward E, Samuels A, Tiwari RC, Ghafoor A, Feuer EJ \& Thun MJ 2005 Cancer statistics. CA: A Cancer Journal for Clinicians 55 10-30. Erratum in: CA: A Cancer Journal for Clinicians $\mathbf{5 5} 259$.

Juul A 2003 Serum levels of insulin-like growth factor I and its binding proteins in health and disease. Growth Hormone and IGF Research 13 113-170.

Kalli KR \& Conover CA 2003 The insulin-like growth factor/insulin system in epithelial ovarian cancer. Frontiers in Bioscience 8 d714-d722.

Khandwala HM, McCutcheon IE, Flyvbjerg A \& Friend KE 2000 The effects of insulin-like growth factors on tumorigenesis and neoplastic growth. Endocrine Reviews 21 215-244.

Larsson O, Girnita A \& Girnita L 2005 Role of insulin-like growth factor 1 receptor signalling in cancer. British Journal of Cancer 92 2097-2101.

Levi F, Lucchini F, Negri E, Boyle P \& La Vecchia C 2004 Cancer mortality in Europe, 1995-999, and an overview of trends since 1960. International Journal of Cancer 2004 110 155-169. Erratum in: International Journal of Cancer 111981.

Lukanova A \& Kaaks R 2005 Endogenous hormones and ovarian cancer: epidemiology and current hypotheses. Cancer Epidemiology, Biomarkers and Prevention 14 98-107.

Lukanova A, Toniolo P, Akhmedkhanov A, Hunt K, Rinaldi S, Zeleniuch-Jacquotte A, Haley NJ, Riboli E, Stattin P, Lundin E et al. 2001 A cross-sectional study of IGF-I determinants in women. European Journal of Cancer Prevention 10 443-452.

Lukanova A, Lundin E, Toniolo P, Micheli A, Akhmedkhanov A, Rinaldi S et al. 2002a Circulating levels of insulin-like growth factor-I and risk of ovarian cancer. International Journal of Cancer 101 549-554.

Lukanova A, Toniolo P, Lundin E, Micheli A, Akhmedkhanov A, Muti P, Zeleniuch-Jacquotte A, Biessy C, Lenner P, Krogh V et al. $2002 b$ Body mass index in relation to ovarian cancer: a multi-centre nested case-control study. International Journal of Cancer 99 603-608.
Lund PK 1999 Insulin-like growth factors: gene structure and regulation. In Hormonal Control of Growth, pp 537-571. Eds JL Kostyo \& HM Goodman. New York: Oxford University Press.

Ma J, Pollak MN, Giovannucci E, Chan JM, Tao Y, Hennekens CH \& Stampfer MJ 1999 Prospective study on colorectal cancer risk in men and plasma levels of insulin-like growth factor (IGF)-I and IGF-binding protein-3. Journal of the National Cancer Institute 91 620-625.

Palmqvist R, Hallmans G, Rinaldi S, Biessy S, Stenling R, Riboli E \& Kaaks R 2002 Plasma IGF-I, IGF-binding protein-3 and risk of colorectal cancer: a prospective study in northern Sweden. Gut 50 642-646.

Pollak MN, Schernhammer ES \& Hankinson SE 2004 Insulin-like growth factors and Neoplasia. Nature Reviews Cancer 4 505-518.

Riboli E, Hunt KJ, Slimani N, Ferrari P, Norat T, Fahey M, Charrondiere UR, Hemon B, Casagrande C, Vignat J et al. 2002 European Prospective Investigation into Cancer and Nutrition (EPIC): study populations and data collection. Public Health Nutrition 5 1113-1124.

Risch HA 1998 Hormonal etiology of epithelial ovarian cancer, with a hypothesis concerning the role of androgens and progesterone. Journal of the National Cancer Institute 90 1774-1786.

Sant M, Aareleid T, Berrino F, Bielska Lasota M, Carli PM, Carli J, Grosclaude P, Hedelin G, Matsuda T, Moller H et al. 2003 EUROCARE working group. EUROCARE-3: survival of cancer patients diagnosed 1990-94 - results and commentary. Annals of Oncology 14 v61-v118.

Stattin P, Byland A, Rinaldi S, Biessy C, Dechaud H, Stenman UH, Egevad L, Riboli E, Hallmans G \& Kaaks R 2000 Plasma insulin-like growth factor-I, insulin-like growth factor-binding proteins, and prostate cancer risk: a prospective study. Journal of the National Cancer Institute 92 1910-1917.

Suikkari AM, Tiitinen A, Stenman UH, Seppala M \& Laatikainen T 1991 Oral contraceptives increase insulinlike growth factor binding protein-1 concentration in women with polycystic ovarian disease. Fertility and Sterility 55 895-899.

Toniolo P, Bruning PF, Akhmedkhanov A, Bronfrer JM, Koenig KL, Lukanova A, Shore RE \& ZeleniuchJacquotte A 2000 Serum insulin-like growth factor-I and breast cancer. International Journal of Cancer $\mathbf{8 8}$ 828-832.

Wang HS \& Chard T 1999 IGFs and IGF-binding proteins in the regulation of human ovarian and endometrial function. Journal of Endocrinology $1611-13$. 